\title{
LEED vs Estidama
}

\author{
Waseem M Hamweyah*
}

American University of Sharjah, UAE

*Corresponding author:Waseem M Hamweyah, American University of Sharjah, UAE, Tel: +966506664714; Email: w.hamweyah@gmail.com

Submission: 眥 March 29, 2018; Published: 囬 April 05, 2018

\section{Short Communication}

In the past few decades, the United Arab Emirates has set a great model for developing countries. Placing itself at the forefront of many industries, breaking records and embodying that the sky is the limit, UAE had to stay up-to-date with all of industries taking place in it. As the construction industry is of UAE's most strong suits, contributing $11 \%$ of the total GDP, and for being globally known to build one the best skylines in the middle of the desert in a pretty short period of time; the Leadership of the United Arab Emirates foresaw the importance of the sustainable built environments. Having to step down that road, UAE's government had to set processes, goals and measures to ensure an incremental success along the way. Starting from that point, a vision has been set in which improving air quality, preservation of natural resources, clean energy, waste management and implementing green growth is heavily considered. Having a mindset and goals ready, there was nothing else left to start this journey but to identify the tools in which industry professionals can measure against to determine how effective their efforts are.

Of the most established tools in regards to sustainability is the US Green Building Council's, which is an American national non-profit membership attracting paying members and aiming to change the construction industry and support sustainability, system; Leadership in Energy and Environmental Design "LEED". LEED has been used globally and even in the UAE. However, Abu Dhabi Urban Planning Council has decided to take sustainability support a step further to account for the culture and the climate of UAE in specific and created the Pearl Rating System on the pillars of environment, economy, climate and culture. As opposed to Economy, Environment and Social Responsibility in LEED. Now as those rating systems are available, and already in use, in the UAE's construction industry, the question of which rating system is more effective and more stringent arises. To answer this question, a closer look into both systems shall be taken. A major difference between LEED and Pearl Rating System is that the last enforces the integrative design process rather than just rewarding it as the Pearl Rating System requires projects to perform some analyses such as: solar and contextual, energy efficiency and water budgeting. In Addition, pearl rating system being part of the UAE's vision ties it closely to the industry's regulations as the building codes in UAE integrate Pearl Rating System's requirements. Doing so, puts any building in UAE few steps into the pearl certification process just by getting the permits. As for the rating process, Pearl Rating System is quite similar to LEED as it features 5 levels of certification (1-5 pearls) as opposed to LEED's 4 levels (Platinum, Gold, Silver and Certified). However the standard of pearl rating system is much higher than LEED, 90\% improvement of benchmark for 5-pearls opposed to $73 \%$ for LEED Platinum. In addition and as the Pearl Rating System is tailored for UAE's construction industry, the weight of categories, in which a structure/development are rewarded, differs, pearl emphasizes on water budgeting more, as shown in the Figure 1 below:

\begin{tabular}{|c|c|c|c|}
\hline \multicolumn{2}{|l|}{ PEARLS } & \multicolumn{2}{|l|}{ LEED } \\
\hline Site selection and Natural systems & $16 \%$ & Site Selection & $24.5 \%$ \\
\hline Water & $25 \%$ & Water & $5.5 \%$ \\
\hline Energy & $25 \%$ & Energy & $33 \%$ \\
\hline Materials & $16 \%$ & Materials & $13.5 \%$ \\
\hline Indoor Environmental Quality & $20 \%$ & Indoor Environmental Quality & $14 \%$ \\
\hline Innovation & $2 \%$ & Innovation & $6.5 \%$ \\
\hline Integrated Design Process & $7 \%$ & Regional Priority & $4 \%$ \\
\hline
\end{tabular}

Figure 1: Comparison of the Categories Weight. 
Another key difference between Pearl Rating System and LEED is the assessment process. The pearl system requires an assessor to evaluate the compliance of the project in addition to a qualified professional, who must be part of the design team, to oversee, guide and advise on sustainable approaches and implementation methods to ensure certification. On the other hand, LEED encourages having an accredited professional on the team, but not as a requirement, to provide technical support and help in the web-based submission system. This approach brings more flexibility to the system but significantly reduces the interaction between the project team, both in design and construction, and the US Green Building Council, which could create a lot of voids and possibly miscommunication for both sides.

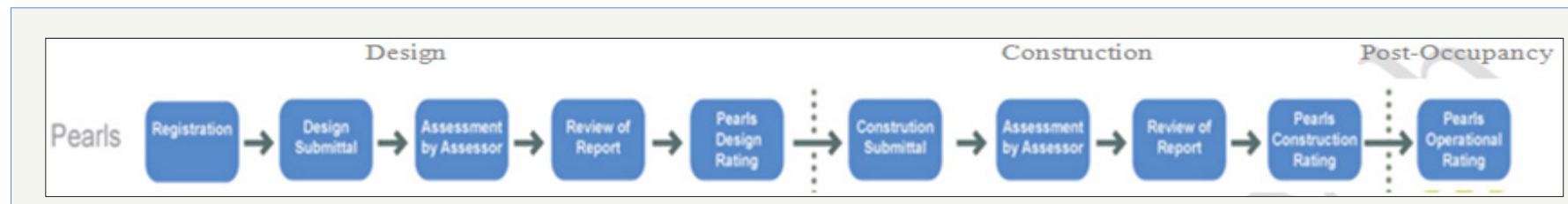

Figure 2: Pearl Certification Process.

Moreover, pearl rating system and LEED differ significantly in terms of certification process. Although both rating systems put out the intention of each credit and leaves it to the project team to decide on the approach to meet the threshold, and prove it through calculation and documentation. But The Pearl Rating System seems to involve its professionals and assessors in more steps along the way from design through construction till post-occupancy, as shown in Figure 2, with three certification for each phase, which progressively ensures the achievement of sustainability goals intended by this rating system. DesignConstruction Post-Occupancy.

On the other side, LEED only monitors the design and construction phases, as shown in Figure 3, offering a design review and certification towards the end of construction, evaluated through online submission. In fairness to LEED, project team is required to provide access to usage data post-occupancy, which could be a sign that there is an intention of including post-occupancy assessment in future versions.

Taking all of the aspects discussed above, I believe that LEED is more flexible than Pearl Rating System. However, the close up involvement of Pearl Rating System in the project cycle ensures the achievement of sustainability goals intended in both systems as it leaves less room for miss documentation, miss interpretation and even manipulation. Moreover, the Pearl Rating System provides more chances for corrective actions during the project's life cycle. In addition, the Pearl Rating System being assessed by governmental entities takes out the commercialism aspect that LEED might need to consider when introducing stricter thresholds or even future credits. Finally and due to the higher standards of Pearl Rating System in general, it seems that pearl rating system is more onerous to achieve than LEED but it serves sustainability goals better [1-4].

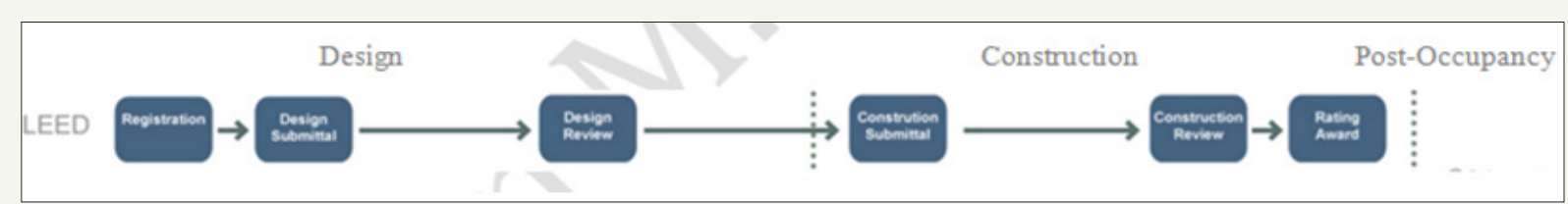

Figure 3: LEED Certification Process.

\section{References}

1. Elgendy K (2016) Comparing Estidama's Pearls Rating System to LEED and BREEAM.

2. https://www.vision2021.ae/en/national-priority-areas/sustainableenvironment-and-infrastructure.
3. Vaibhav A (2016) United Arab Emirates: Highway to sustainability.

4. Khalid KS, Adrian P, Nicholls R (2014) Sustainability Assessment Methods for the Gulf Region. CEPT University, Ahmedabad, India, pp. 1-8.
Creative Commons Attribution 4.0 International License

For possible submissions Click Here Submit Article

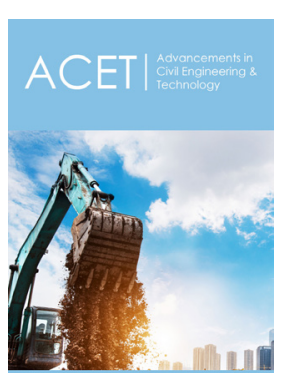

Advancements in Civil Engineering \& Technology

\section{Benefits of Publishing with us}

- High-level peer review and editorial services

- Freely accessible online immediately upon publication

- Authors retain the copyright to their work

- Licensing it under a Creative Commons license

- Visibility through different online platforms 